UNIVERSIDADE DE SÃO PAULO

FACULDADE DE ECONOMIA, ADMINISTRAÇÃO E CONTABILIDADE DEPARTAMENTO DE ADMINISTRAÇÃO

PROGRAMA DE PÓS-GRADUAÇÃO EM ADMINISTRAÇÃO

A INSERÇÃO DE PRINCÍPIOS ÉTICOS NA GESTÃO EMPRESARIAL

Cinthia Moreira Pfannemüller

Orientador: Prof. Dr. Martinho Isnard R. de Almeida

SÃO PAULO 
Profa. Dra. Suely Vilela

Reitora da Universidade de São Paulo

Prof. Dr. Carlos Roberto Azzoni

Diretor da Faculdade de Economia, Administração e Contabilidade

Prof. Dr. Isak Kruglianskas

Chefe do Departamento de Administração

Prof. Dr. Lindolfo Galvão de Albuquerque

Coordenador do Programa de Pós-Graduação em Administração 
CINTHIA MOREIRA PFANNEMÜLLER

\section{A INSERÇÃO DE PRINCÍPIOS ÉTICOS NA GESTÃO EMPRESARIAL}

Dissertação apresentada ao Departamento de Administração da Faculdade de Economia, Administração e Contabilidade da Universidade de São Paulo como requisito para a obtenção do título de Mestre em Administração.

Orientador: Prof. Dr. Martinho Isnard R. de Almeida

SÃO PAULO 
Pfannemüller, Cinthia Moreira

A inserção de princípios éticos na gestão empresarial / Cinthia Moreira Pfannemüller. -- São Paulo, 2006.

$94 \mathrm{p}$.

Dissertação (Mestrado) - Universidade de São Paulo, 2006

Bibliografia.

1. Ética comercial 2. Ética 3. Administração de empresas 4. Responsabilidade social I. Universidade de São Paulo. Faculdade de Economia, Administração e Contabilidade II. Título. 